\title{
The relationship between sleep disturbances and quality of life in elderly patients with hypertension
}

This article was published in the following Dove Medical Press journal: Clinical Interventions in Aging

\section{Izabella Uchmanowicz' Karolina Markiewicz' \\ Bartosz Uchmanowicz' Aleksandra Kołtuniuk ${ }^{2}$ Joanna Rosińczuk ${ }^{2}$}

'Department of Clinical Nursing, Faculty of Health Sciences, Wroclaw Medical University, 5I-6I8 Wroclaw, Poland; ${ }^{2}$ Department of Nervous System Diseases, Faculty of Health Sciences, Wroclaw Medical University, 5|-6|8 Wroclaw, Poland
Correspondence: Izabella Uchmanowicz Division of Nursing in Internal Medicine Procedures, Department of Clinical Nursing, Faculty of Health Sciences, Wroclaw Medical University, Bartla 5, 5I-618 Wroclaw, Poland

Tel +48 7I 784 I8 24

Fax +48713459324

Email izabella.uchmanowicz@umed.wroc.pl
Purpose: Sleep disorders, such as insomnia with objective short sleep duration, are associated with increased risk of hypertension. The objective of the study was to evaluate the effects of insomnia and daytime sleepiness on the quality of life (QOL) among elderly hypertensive patients. Patients and methods: This cross-sectional study covered 100 patients with hypertension. All participants completed standardized questionnaires, such as the Epworth Sleepiness Scale (ESS), the Athens Insomnia Scale (AIS), and the World Health Organization Quality of LifeBrief (WHOQOL-BREF), and clinical data were obtained from patients' medical records.

Results: We showed that more than half of the patients experienced insomnia (AIS score $\geq 6$ ) and 39\% experienced daytime sleepiness. Daytime sleepiness was negatively associated with perceived QOL $(r=-0.478, P<0.001)$. It was also shown that insomnia might be influenced by older age $(P<0.001)$, occupational activity $(P=0.011)$, overweight (body mass index [BMI] 25-30) $(P=0.042)$, and longer duration of illness $(P=0.049)$ among hypertensive patients.

Conclusion: Sleep problems have a significant negative impact on the QOL in patients with hypertension, especially in the physical domain of the QOL questionnaire. The occurrence of sleep problems in patients with hypertension is influenced by older age, primary education, overweight, occupational activity, and longer duration of illness.

Keywords: daytime sleepiness, hypertension, insomnia, sleep problems, quality of life, Epworth Sleepiness Scale, Athens Insomnia Scale

\section{Introduction}

Hypertension is a major risk factor for cardiovascular disease, including stroke, and

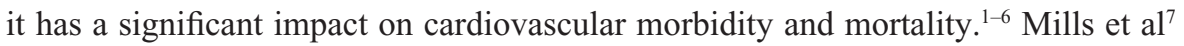
estimated that in 2010, the global prevalence of hypertension was 1.39 billion ( $31 \%$ of all adults), representing a 5.2\% increase in global prevalence between 2000 and 2017. Previous studies ${ }^{8-12}$ have shown that people with hypertension have poorer sleep quality than those with normal blood pressure. It has also been shown that sleep problems are associated with an increased risk of hypertension ${ }^{10,12-14}$ and vascular inflammation ${ }^{15}$ with uncontrolled and treatment-resistant hypertension ${ }^{16}$ and with higher all-cause mortality rates. ${ }^{17}$ The results of a study by $\mathrm{Li}$ et al ${ }^{18}$ have shown that treatment of sleep disorders in hypertensive patients can decrease blood pressure.

Sleep problems, ie, insomnia or excessive daytime sleepiness, are widespread in the general population (about one-third of people suffer from them) and hence is a significant clinical problem. ${ }^{19}$ Most often, insomnia is defined by the presence of subjective report of difficulty with sleep resulting in too little sleep or poor-quality sleep. ${ }^{20}$ The general definition of insomnia according to the third edition of the International Classification of Sleep Disorders (ICSD-3) published by the American Academy of Sleep Medicine Board of Directors is characterized by "a persistent difficulty with 
sleep initiation, duration, consolidation, or quality that occurs despite adequate opportunity and circumstances for sleep, and results in some form of daytime impairment," ${ }^{21}$ whereas excessive daytime sleepiness, according to the ICSD, is only a symptom of sleep disorders or other illnesses. ${ }^{19}$

In a holistic view of health and disease, health-related quality of life (HRQOL) is a key component of health assessment, just as important as the assessment of medical indicators. Achieving improvement in either of these two abovementioned areas is considered a success. ${ }^{22}$ In the literature, there is a strong correlation between QOL and one's general state of health. The assessment of HRQOL is particularly important in the context of chronic illness, in which the return to complete efficiency is very difficult or even impossible to achieve.

Moreover, QOL assessment is helpful in evaluating the effectiveness of treatment procedures and modifying them when it is necessary. ${ }^{23}$ The main goals of the assessment of QOL in patients with hypertension include improvement of the quality of provided services, selection of the relevant treatment options or modifying them, individualization of pharmacological treatment, or detection of the adverse reactions during antihypertensive therapy. ${ }^{24}$

QOL assessment in patients with hypertension is difficult due to the time needed to achieve the effects of the therapy. Antihypertensive therapy is long lasting, and the patient does not notice the results immediately. Undoubtedly, numerous studies underline decreased QOL in patients with hypertension in comparison to the healthy population. ${ }^{25-27}$

The lowest QOL scores among hypertensive patients are found in terms of physical activity, daily activities related to health, general health, and emotional state. Using effective antihypertensive treatment can reduce the gap between the QOL scores in patients with hypertension and those in the healthy population. ${ }^{28}$

Factors influencing the HRQOL of patients with hypertension are divided into three groups as follows: sociodemographic, clinical, and other/non-specific. The first group includes age, sex, education, as well as genetic and familial conditions of hypertension. Clinical factors include blood pressure, the presence of organ damage and side effects, comorbidities, the number and types of medications used, and the presence of side effects of pharmacotherapy, obesity, and sexual dysfunctions. Other/non-specific factors are disease diagnosis (the effect of labeling), physical activity, and psychological stress. ${ }^{29}$

A high HRQOL rating means that a person, in spite of his/her illness, perceives himself/herself as functioning well in every area, whereas a low HRQOL value shows that the disease is a limitation and is an obstacle to proper functioning.

Every disease is also associated with the financial burden associated with treatment. Taking into consideration the above, the risk of psychological disorders is much higher in those with chronic illness than in the healthy population. Fear of threats to one's health, sometimes even to one's life, leads to mood diminishment or depression. Mental illnesses should not be underestimated; they represent a serious threat to the course of the therapeutic process. Long-term chronic patients learn to live in a "new" situation and to deal with various chronic conditions. ${ }^{29}$

Undoubtedly, QOL is a very important issue in antihypertensive therapy. Both pharmacological and nonpharmacological treatments cause normalization of pressure and reduce the risk of organ complications that contribute to a poorer QOL. Appropriate hypertensive therapy that involves the choice of the right medication group and the individualization of treatment may contribute to QOL improvement and thus encourage the patient to cooperate and adhere to therapeutic recommendations.

It has been shown that sleep affects vitality and health status $^{10}$ and that sleep problems affect daily functioning ${ }^{30}$ and QOL, ${ }^{8,31-36}$ and so it can be assumed that in patients with hypertension, sleep problems will have a negative effect on QOL, but this has not been investigated.

Therefore, the aim of this study is to evaluate the relationship between insomnia and daytime sleepiness and the QOL in elderly patients being treated for hypertension.

\section{Patients and methods \\ Study design and settings}

This cross-sectional study was conducted from September 2016 to June 2017. The STrengthening the Reporting of Observational studies in Epidemiology (STROBE) guidelines for reporting of observational studies were followed.

\section{Study participants and selection}

The study sample was a group of 100 patients being treated for hypertension in the Clinic of Angiology, Hypertension, and Diabetology at the University Clinical Hospital in Wroclaw, Poland. Inclusion criteria were as follows: 1) age over 18 years; 2) clinically diagnosed hypertension for more than 6 months; 3) absence of mental disorder; and (4) signed informed consent to participate in the study. Exclusion criteria were as follows: 1) previous diagnosis or treatment for sleep problems, eg, sleeping pills and/or antidepressants; 
2) previous diagnosis of mental disorder, eg, depression and/or anxiety, and 3) night shift work.

\section{Ethical considerations}

The research was approved by the Bioethics Committee of the Wroclaw Medical University, Poland (approval number KB-388/2017). The investigation conforms to the principles outlined in the Declaration of Helsinki and recommendations of Good Clinical Practice. Participation in this study was anonymous and voluntary. All participants gave written informed consent at the beginning of the study. They were also informed of its purpose and of the possibility to withdraw participation at any stage. The dignity and rights of participants were respected at all times.

\section{Research instruments}

Participants completed several standardized questionnaires such as the Epworth Sleepiness Scale (ESS), ${ }^{37}$ the Athens Insomnia Scale (AIS), ${ }^{38}$ the Polish version of the World Health Organization Quality of Life-Brief (WHOQOLBREF), ${ }^{39}$ and the questionnaire designed by the authors for purposes of this study.

The questionnaire designed by the authors is a nonvalidated, self-administered survey that has been designed specifically to be completed by patients with hypertension and collects sociodemographic data (age, sex, height, weight, body mass index [BMI], place of residence, education, marital status, and occupational activity) and includes questions about clinical conditions (hypertension stage, comorbidities, frequency of blood pressure measurements, ability to recognize symptoms of hypertension, knowledge of hypertension complications, past hospitalizations due to hypertension, and recent medications).

The ESS is a self-reported scale used for the assessment of daytime sleepiness. Respondents are asked to rate, on a fourpoint scale (0-3), their usual chances of dozing off or falling asleep while engaged in eight different activities. Overall score ranges from 0 to 24 points, with higher scores indicating greater daytime sleepiness. In general, ESS scores can be interpreted as follows: 0-5 lower normal daytime sleepiness; 6-10 higher normal daytime sleepiness; 11-12 mild excessive daytime sleepiness; $13-15$ moderate excessive daytime sleepiness; and 16-24 severe excessive daytime sleepiness. ${ }^{37}$

The AIS is a self-administered psychometric instrument designed to quantify sleep difficulty. It consists of eight items as follows: the first five pertain to sleep induction, awakenings during the night, final awakening, total sleep duration, and sleep quality, whereas the last three refer to well-being, functioning capacity, and sleepiness during the day. A cutoff score of $\geq 6$ on the AIS is used to establish the diagnosis of insomnia. ${ }^{38}$ Internal consistency as measured by Cronbach's alpha was 0.89 in our sample.

The WHOQOL-BREF consists of 26 questions assessing the respondents' overall perception of their HRQOL that gives an overall picture of their health condition. Responses to the first two questions that correspond to the perception of QOL and satisfaction from health were analyzed separately. The remaining 24 questions assess the four domains of the QOL (physical, psychological, social, and environmental QOL). Responses are given using a five-point scale (1-5). QOL in each domain was expressed as a mean value, according to the key and guidelines provided by Wołowicka and Jaracz. ${ }^{39}$ Higher scores indicate better QOL.

\section{Data analysis}

Descriptive statistics (mean, SD, median, quartiles, minimum, and maximum) were calculated for continuous variables. Categorical variables were described as frequencies and percentages of each category. Relationships between categorical variables were analyzed using the chi-squared test (with Yates correction for $2 \times 2$ tables) or Fisher's exact test in cases where expected frequencies were low. Normality was checked with the Shapiro-Wilk test. Group differences in continuous variables were analyzed using Student's $t$-test (for parametric variables) or the Mann-Whitney test (for non-parametric variables) where there were only two groups. ANOVA (normally distributed variables) or the Kruskal-Wallis test (non-normally distributed variables) was used to analyze group differences where there were three or more groups. Overall effects were subjected to post hoc analysis using Tukey's HSD test (parametric variables) or Dunn's test (non-parametric variables). Correlations between continuous variables were analyzed using Pearson's (for a normal distribution) or Spearman's correlation coefficient (for non-normal distribution). Correlation coefficients were interpreted as follows: $|r| \geq 0.9$ - very strong correlation; $0.7 \leq|\mathrm{r}|<0.9$ - strong correlation; $0.5 \leq|\mathrm{r}|<0.7$ - moderately strong correlation; $0.3 \leq|\mathrm{r}|<0.5$ - weak correlation; and $|r| \geq 0.3$ - very weak (negligible) correlation. ${ }^{40}$ In all analyses, the level of statistical significance was set at $P<0.05$. The analyses were conducted with $\mathrm{R}$ software version 3.3.2.

\section{Results}

This study was undertaken among 100 patients with hypertension (54 men and 46 women). The mean age was $65.5 \pm 15.6$ years. The detailed sociodemographic characteristics of the study participants are shown in Tables 1 and 2. 
Table I Sociodemographic and clinical data of persons with and without drowsiness

\begin{tabular}{|c|c|c|c|c|c|c|c|}
\hline \multirow[t]{2}{*}{ Features } & \multicolumn{2}{|c|}{ Drowsiness $(\mathrm{N}=39)$} & \multicolumn{2}{|c|}{$\begin{array}{l}\text { Lack of } \\
\text { drowsiness } \\
(\mathrm{N}=6 \mathrm{I})\end{array}$} & \multicolumn{2}{|c|}{$\begin{array}{l}\text { Total } \\
(\mathbf{N}=\mid 00)\end{array}$} & \multirow[t]{2}{*}{$P^{a}$} \\
\hline & $\mathbf{N}$ & $\%$ & $\mathbf{N}$ & $\%$ & $\mathbf{N}$ & $\%$ & \\
\hline \multicolumn{8}{|l|}{ Sex } \\
\hline Female & 16 & 41.03 & 30 & 49.18 & 46 & 46.00 & 0.554 \\
\hline Male & 23 & 58.97 & 31 & 50.82 & 54 & 54.00 & \\
\hline \multicolumn{8}{|l|}{ BMI } \\
\hline 18.5-25: normal weight & 7 & 17.95 & 23 & 37.70 & 30 & 30.00 & 0.064 \\
\hline 25-30: overweight & 23 & 58.97 & 26 & 42.62 & 49 & 49.00 & \\
\hline 30-35: obesity & 9 & 23.08 & 8 & 13.11 & 17 & 17.00 & \\
\hline 35-40: obesity $I^{\circ}$ & 0 & 0.00 & 1 & 1.64 & 1 & 1.00 & \\
\hline$>40$ : obesity $1 \mathrm{II}^{\circ}$ & 0 & 0.00 & 3 & 4.92 & 3 & 3.00 & \\
\hline \multicolumn{8}{|l|}{ Marital status } \\
\hline Single & 20 & 51.28 & 28 & 45.90 & 48 & 48.00 & 0.749 \\
\hline In relationship & 19 & 48.72 & 33 & 54.10 & 52 & 52.00 & \\
\hline \multicolumn{8}{|l|}{ Education } \\
\hline Primary & 11 & 28.21 & 11 & 18.03 & 22 & 22.00 & 0.037 \\
\hline Secondary & 22 & 56.41 & 26 & 42.62 & 48 & 48.00 & \\
\hline Higher & 6 & 15.38 & 24 & 39.34 & 30 & 30.00 & \\
\hline \multicolumn{8}{|l|}{ Place of residence } \\
\hline City & 17 & 43.59 & 34 & 55.74 & 51 & 51.00 & 0.327 \\
\hline Countryside & 22 & 56.41 & 27 & 44.26 & 49 & 49.00 & \\
\hline \multicolumn{8}{|l|}{ Occupational activity } \\
\hline Working & 16 & 41.03 & 39 & 63.93 & 55 & 55.00 & 0.041 \\
\hline Not working & 23 & 58.97 & 22 & 36.07 & 45 & 45.00 & \\
\hline \multicolumn{8}{|l|}{ Hypertension } \\
\hline Stage I & 3 & 7.69 & 14 & 22.95 & 17 & 17.00 & 0.139 \\
\hline Stage 2 & 22 & 56.41 & 28 & 45.90 & 50 & 50.00 & \\
\hline Stage 3 & 14 & 35.90 & 19 & 31.15 & 33 & 33.00 & \\
\hline \multicolumn{8}{|l|}{ Comorbidities } \\
\hline Diabetes & 20 & 51.28 & 13 & 21.31 & 33 & 33.00 & 0.004 \\
\hline Hypercholesterolemia & 16 & 41.03 & 35 & 57.38 & 51 & 51.00 & 0.164 \\
\hline Ischemic heart disease & 12 & 30.77 & 15 & 24.59 & 27 & 27.00 & 0.654 \\
\hline Renal failure & 8 & 20.51 & 4 & 6.56 & 12 & 12.00 & 0.056 \\
\hline Heart failure & 2 & 5.13 & 4 & 6.56 & 6 & 6.00 & 1 \\
\hline \multicolumn{8}{|l|}{ Blood pressure measurement } \\
\hline $2-3$ a day & 2 & 5.13 & 7 & 11.48 & 9 & 9.00 & 0.651 \\
\hline Once a day & 14 & 35.90 & 24 & 39.34 & 38 & 38.00 & \\
\hline Once a week & 9 & 23.08 & 10 & 16.39 & 19 & 19.00 & \\
\hline When feeling bad & 14 & 35.90 & 20 & 32.79 & 34 & 34.00 & \\
\hline \multicolumn{8}{|c|}{ Ability to recognize symptoms of hypertension } \\
\hline Yes & 16 & 41.03 & 43 & 70.49 & 59 & 59.00 & 0.007 \\
\hline No & 23 & 58.97 & 18 & 29.51 & 41 & 41.00 & \\
\hline \multicolumn{8}{|c|}{ Knowledge of hypertension complications } \\
\hline Yes & 12 & 30.77 & 37 & 60.66 & 49 & 49.00 & 0.007 \\
\hline No & 27 & 69.23 & 24 & 39.34 & 51 & 51.00 & \\
\hline
\end{tabular}


Table I (Continued)

\begin{tabular}{|c|c|c|c|c|c|c|c|c|c|}
\hline \multirow{2}{*}{\multicolumn{3}{|c|}{ Features }} & \multicolumn{2}{|c|}{ Drowsiness $(\mathrm{N}=39)$} & \multicolumn{2}{|c|}{$\begin{array}{l}\text { Lack of } \\
\text { drowsiness } \\
(\mathrm{N}=6 \mathrm{I})\end{array}$} & \multicolumn{2}{|c|}{$\begin{array}{l}\text { Total } \\
(\mathbf{N}=\mid 00)\end{array}$} & \multirow[t]{2}{*}{$P^{a}$} \\
\hline & & & $\mathbf{N}$ & $\%$ & $\mathbf{N}$ & $\%$ & $\mathbf{N}$ & $\%$ & \\
\hline \multicolumn{10}{|c|}{ Hospitalizations due to hypertension } \\
\hline \multicolumn{3}{|l|}{$1-2$} & 19 & 48.72 & 47 & 77.05 & 66 & 66.00 & 0.007 \\
\hline \multicolumn{3}{|l|}{$3-5$} & 20 & 51.28 & 14 & 22.95 & 34 & 34.00 & \\
\hline \multicolumn{10}{|l|}{ Medications } \\
\hline \multicolumn{3}{|c|}{ Angiotensin-converting enzyme } & 3 & 7.69 & 13 & 21.31 & 16 & 16.00 & 0.125 \\
\hline \multicolumn{3}{|c|}{ Angiotensin receptor antagonists } & 13 & 33.33 & 20 & 32.79 & 33 & 33.00 & 1 \\
\hline \multicolumn{3}{|l|}{ Diuretics } & 13 & 33.33 & 15 & 24.59 & 28 & 28.00 & 0.471 \\
\hline \multicolumn{3}{|l|}{ Adrenergic blockers } & 14 & 35.90 & 14 & 22.95 & 28 & 28.00 & 0.239 \\
\hline \multicolumn{3}{|c|}{ Calcium channel blockers } & 3 & 7.69 & 7 & 11.48 & 10 & 10.00 & 0.736 \\
\hline \multirow[t]{2}{*}{ Features } & \multicolumn{2}{|c|}{ Drowsiness $(\mathbf{N}=\mathbf{3 9})$} & \multicolumn{3}{|c|}{ Lack of drowsiness $(\mathrm{N}=6 \mathrm{I})$} & \multicolumn{3}{|c|}{ Total $(\mathbf{N}=100)$} & \multirow[t]{2}{*}{$P^{b}$} \\
\hline & $M(S D)$ & Me (QI-Q3) & $M(S D)$ & \multicolumn{2}{|c|}{ Me (QI-Q3) } & $M(S D)$ & \multicolumn{2}{|c|}{ Me (QI-Q3) } & \\
\hline Age (years) & $69.8(14.2)$ & $70(6 I-79.5)$ & $60.9(15.6)$ & \multicolumn{2}{|c|}{$64(49-70)$} & $64.4(15.6)$ & \multicolumn{2}{|c|}{$65.5(52-77)$} & 0.005 \\
\hline High $(\mathrm{cm})$ & $168.5(10.8)$ & $172(163.5-178.5)$ & $170.3(10.8)$ & \multicolumn{2}{|c|}{$170(165-179)$} & $169.6(10.8)$ & \multicolumn{2}{|c|}{$170(164-179)$} & 0.557 \\
\hline Weight (kg) & $78.4(12.8)$ & 78 (69-89) & $77.8(13.8)$ & \multicolumn{2}{|c|}{$76(69-85)$} & $78.1(13.3)$ & \multicolumn{2}{|c|}{76.5 (69-88) } & 0.761 \\
\hline Disease duration (years) & $16.9(7.6)$ & $15(|1-2| .5)$ & | 3.7 (7.8) & \multicolumn{2}{|c|}{$13(7-18)$} & $15(7.8)$ & \multicolumn{2}{|c|}{$14(9.8-20)$} & 0.049 \\
\hline
\end{tabular}

Notes: aFor BMI, renal and heart failure, the frequency of blood pressure measurements, and intake of calcium channel blockers - the exact Fisher's test (due to the low expected values in the table); for other variables - chi-squared test. 'For age - Student's $t$-test (normal distribution); for other variables - Mann-Whitney $U$ test (due to the lack of normal distribution). $\mathrm{N}$, number of patients; $P$, level of statistical significance.

Abbreviations: BMI, body mass index; M, mean; Me, median; QI, first quartile; Q3, third quartile.

Table 2 Sociodemographic and clinical data of persons with and without insomnia

\begin{tabular}{|c|c|c|c|c|c|c|c|}
\hline \multirow[t]{2}{*}{ Features } & \multicolumn{2}{|c|}{ Insomnia (N=59) } & \multicolumn{2}{|c|}{$\begin{array}{l}\text { Lack of } \\
\text { insomnia } \\
(\mathbf{N}=4 I)\end{array}$} & \multicolumn{2}{|c|}{$\begin{array}{l}\text { Total } \\
(\mathbf{N}=\mid 00)\end{array}$} & \multirow[t]{2}{*}{$P^{a}$} \\
\hline & $\mathbf{N}$ & $\%$ & $\mathbf{N}$ & $\%$ & $\mathbf{N}$ & $\%$ & \\
\hline \multicolumn{8}{|l|}{ Sex } \\
\hline Female & 25 & 42.37 & 21 & 51.22 & 46 & 46.00 & 0.503 \\
\hline Male & 34 & 57.63 & 20 & 48.78 & 54 & 54.00 & \\
\hline \multicolumn{8}{|l|}{ BMI } \\
\hline 18.5-25: normal weight & 14 & 23.73 & 16 & 39.02 & 30 & 30.00 & 0.042 \\
\hline 25-30: overweight & 34 & 57.63 & 15 & 36.59 & 49 & 49.00 & \\
\hline 30-35: obesity & 10 & 16.95 & 7 & 17.07 & 17 & 17.00 & \\
\hline 35-40: obesity $11^{\circ}$ & I & 1.69 & 0 & 0.00 & 1 & 1.00 & \\
\hline$>40:$ obesity III ${ }^{\circ}$ & 0 & 0.00 & 3 & 7.32 & 3 & 3.00 & \\
\hline \multicolumn{8}{|l|}{ Marital status } \\
\hline Single & 31 & 52.54 & 17 & 41.46 & 48 & 48.00 & 0.375 \\
\hline In relationship & 28 & 47.46 & 24 & 58.54 & 52 & 52.00 & \\
\hline \multicolumn{8}{|l|}{ Education } \\
\hline Primary & 15 & 25.42 & 7 & 17.07 & 22 & 22.00 & 0.109 \\
\hline Secondary & 31 & 52.54 & 17 & 41.46 & 48 & 48.00 & \\
\hline Higher & 13 & 22.03 & 17 & 41.46 & 30 & 30.00 & \\
\hline \multicolumn{8}{|l|}{ Place of residence } \\
\hline City & 29 & 49.15 & 22 & 53.66 & 51 & 51.00 & 0.81 \\
\hline Countryside & 30 & 50.85 & 19 & 46.34 & 49 & 49.00 & \\
\hline
\end{tabular}


Table 2 (Continued)

\begin{tabular}{|c|c|c|c|c|c|c|c|c|c|}
\hline \multirow{2}{*}{\multicolumn{3}{|c|}{ Features }} & \multicolumn{2}{|c|}{ Insomnia ( $\mathbf{N}=\mathbf{5 9})$} & \multicolumn{2}{|c|}{$\begin{array}{l}\text { Lack of } \\
\text { insomnia } \\
(\mathrm{N}=4 \mathrm{I})\end{array}$} & \multicolumn{2}{|c|}{$\begin{array}{l}\text { Total } \\
(\mathrm{N}=\mid 00)\end{array}$} & \multirow[t]{2}{*}{$P^{a}$} \\
\hline & & & $\mathbf{N}$ & $\%$ & $\mathbf{N}$ & $\%$ & $\mathbf{N}$ & $\%$ & \\
\hline \multicolumn{10}{|l|}{ Occupational activity } \\
\hline \multicolumn{3}{|l|}{ Working } & 25 & 42.37 & 30 & 73.17 & 55 & 55.00 & 0.005 \\
\hline \multicolumn{3}{|l|}{ Not working } & 34 & 57.63 & 11 & 26.83 & 45 & 45.00 & \\
\hline \multicolumn{10}{|l|}{ Hypertension } \\
\hline \multicolumn{3}{|l|}{ Stage I } & 7 & 11.86 & 10 & 24.39 & 17 & 17.00 & 0.014 \\
\hline \multicolumn{3}{|l|}{ Stage 2} & 26 & 44.07 & 24 & 58.54 & 50 & 50.00 & \\
\hline \multicolumn{3}{|l|}{ Stage 3} & 26 & 44.07 & 7 & 17.07 & 33 & 33.00 & \\
\hline \multicolumn{10}{|l|}{ Comorbidities } \\
\hline \multicolumn{3}{|l|}{ Diabetes } & 23 & 38.98 & 10 & 24.39 & 33 & 33.00 & 0.19 \\
\hline \multicolumn{3}{|l|}{ Hypercholesterolemia } & 23 & 38.98 & 28 & 68.29 & 51 & 51.00 & 0.007 \\
\hline \multicolumn{3}{|l|}{ Ischemic heart disease } & 21 & 35.59 & 6 & 14.63 & 27 & 27.00 & 0.036 \\
\hline \multicolumn{3}{|l|}{ Renal failure } & 10 & 16.95 & 2 & 4.88 & 12 & 12.00 & 0.115 \\
\hline \multicolumn{3}{|l|}{ Heart failure } & 5 & 8.47 & 1 & 2.44 & 6 & 6.00 & 0.396 \\
\hline \multicolumn{10}{|c|}{ Blood pressure measurement } \\
\hline \multicolumn{3}{|l|}{$2-3$ a day } & 6 & 10.17 & 3 & 7.32 & 9 & 9.00 & 0.361 \\
\hline \multicolumn{3}{|l|}{ Once a day } & 26 & 44.07 & 12 & 29.27 & 38 & 38.00 & \\
\hline \multicolumn{3}{|l|}{ Once a week } & 9 & 15.25 & 10 & 24.39 & 19 & 19.00 & \\
\hline \multicolumn{3}{|l|}{ When feeling bad } & 18 & 30.51 & 16 & 39.02 & 34 & 34.00 & \\
\hline \multicolumn{10}{|c|}{ Ability to recognize symptoms of hypertension } \\
\hline Yes & & & 29 & 49.15 & 30 & 73.17 & 59 & 59.00 & 0.028 \\
\hline No & & & 30 & 50.85 & 11 & 26.83 & 41 & 41.00 & \\
\hline Knowledge of hypertensic & plications & & & & & & & & \\
\hline Yes & & & 21 & 35.59 & 28 & 68.29 & 49 & 49.00 & 0.003 \\
\hline No & & & 38 & 64.41 & 13 & 31.71 & 51 & 51.00 & \\
\hline Hospitalizations due to hy & sion & & & & & & & & \\
\hline $\mathrm{I}-2$ & & & 29 & 49.15 & 37 & 90.24 & 66 & 66.00 & $<0.001$ \\
\hline $3-5$ & & & 30 & 50.85 & 4 & 9.76 & 34 & 34.00 & \\
\hline Medications & & & & & & & & & \\
\hline Angiotensin-converting & & & 10 & 16.95 & 6 & 14.63 & 16 & 16.00 & 0.973 \\
\hline Angiotensin receptor a & & & 23 & 38.98 & 10 & 24.39 & 33 & 33.00 & 0.19 \\
\hline Diuretics & & & 18 & 30.51 & 10 & 24.39 & 28 & 28.00 & 0.657 \\
\hline Adrenergic blockers & & & 15 & 25.42 & 13 & 31.71 & 28 & 28.00 & 0.644 \\
\hline Calcium channel blocke & & & 5 & 8.47 & 5 & 12.20 & 10 & 10.00 & 0.736 \\
\hline Features & Insomnia (I & $I=39$ ) & Lack of ins & iia $(N=$ & & Total $(\mathbf{N}=\mathbf{I}$ & & & $P^{\mathrm{b}}$ \\
\hline & $M(S D)$ & Me (QI-Q3) & $M(S D)$ & $\operatorname{Me}(C$ & & $M(S D)$ & Me & QI-Q3) & \\
\hline Age (years) & $69.4(14.6)$ & $70(60.5-80)$ & $57.1(14.2)$ & $59(49$ & & $64.4(15.6)$ & 65.5 & (52-77) & $<0.001$ \\
\hline High $(\mathrm{cm})$ & $168.2(10.5)$ & $169(161-174.5)$ & $171.7(11)$ & 1711 & & $169.6(10.8)$ & 170 & |64-179) & 0.053 \\
\hline Weight (kg) & $76.6(11.1)$ & 78 (69-88) & $80.1(16)$ & $75(70$ & & $78.1(13.3)$ & 76.5 & (69-88) & 0.521 \\
\hline Disease duration (years) & $16.7(7.9)$ & $15(11-22)$ & $12.5(7.1)$ & $12(7-$ & & $15(7.8)$ & 14 & .8-20) & 0.049 \\
\hline
\end{tabular}

Notes: ${ }^{a}$ For BMI, renal and heart failure, the frequency of blood pressure measurements, and intake of calcium channel blockers - the exact Fisher's test (due to the low expected values in the table); for other variables - chi-squared test. 'For age - Student's $t$-test (normal distribution); for other variables - Mann-Whitney $U$ test (due to the lack of normal distribution). $\mathrm{N}$, number of patients; $P$, level of statistical significance.

Abbreviations: BMI, body mass index; M, mean; Me, median; QI, first quartile; Q3, third quartile. 
We showed that $39 \%$ of the patients reported daytime sleepiness ( $37 \%$ mild and $2 \%$ moderate) on the ESS scale, and $59 \%$ were suffering from insomnia according to the AIS scale. Mean levels of QOL and health perception according to the WHOWOL-BREF scale were $3.68 \pm 0.68$ and $3.24 \pm 0.65$, respectively. Particular results for each domain were $13.8 \pm 2.27$ for physical, $13.24 \pm 2.23$ for psychological, $14.73 \pm 3.32$ for social, and $13.19 \pm 2.41$ for environmental.

Daytime sleepiness was more common in the elderly ( $P=0.005)$, the less well-educated $(P=0.03)$, and the nonoccupational $(P=0.04)$. Sleepiness was also more common in patients with longer duration of hypertension $(P=0.049)$, with diabetes as a comorbidity $(P=0.004)$, who are characterized by the lack of knowledge about symptoms of hypertension $(P=0.007)$, and its complications $(P=0.007)$ and patients who were more frequently hospitalized due to complications of hypertension $(P=0.007)$. The results are presented in Table 1 .

Insomnia was more common in participants who were elderly $(P<0.001)$, non-working $(P=0.005)$, overweight $(P=0.042)$, clinically diagnosed with third stage hypertension ( $P=0.014)$, clinically diagnosed with comorbid hypercholesterolemia $(P=0.007)$ or ischemic heart disease $(P=0.036)$, characterized by a lack of knowledge about the symptoms of hypertension $(P=0.028)$ or complications of hypertension $(P=0.003)$, and patients who were more frequently hospitalized due to complications of hypertension $(P<0.001)$. The results are presented in Table 2.

Many of the sociodemographic variables were associated with both sleepiness and insomnia. The results are presented in Tables 3 and 4.

We also found that sleepiness affected all domains of QOL in patients with hypertension: the greater their daytime sleepiness, the lower their QOL. Daytime sleepiness had the greatest effect on physical QOL $(r=-0.565, P<0.001)$ and psychological QOL $(r=-0.554, P<0.001)$. Insomnia affected the QOL in patients with hypertension. There was a negative correlation between AIS score and all domains of QOL as measured by the WHOQOL-BREF. Insomnia had most effect on physical $(r=-0.582, P<0.001)$ and psychological domain of QOL $(r=-0.520, P<0.001)$. The results are presented in Table 5.

The results for the relationship between sleep disturbances for all domains of the ESS questionnaire and QOL perception are presented in Figure 1.

\section{Discussion}

Insomnia is one of the most common sleep problems, and because of its prevalence, it is a serious problem in the
Table 3 Correlations between sociodemographic variables and the result of the ESS questionnaire

\begin{tabular}{|c|c|c|c|}
\hline \multirow[t]{2}{*}{ Variables } & \multicolumn{2}{|c|}{$\begin{array}{l}\text { Spearman correlation } \\
\text { coefficient (rho) }\end{array}$} & \multirow[t]{2}{*}{$P^{a}$} \\
\hline & $M(S D)$ & Me (QI-Q3) & \\
\hline Age & \multicolumn{2}{|l|}{ rho $=0.338$} & 0.001 \\
\hline Disease duration & \multicolumn{2}{|l|}{ rho $=0.248$} & 0.013 \\
\hline \multicolumn{4}{|l|}{ Sex } \\
\hline Female & $9.35(2.84)$ & $9(8-12)$ & 0.379 \\
\hline Male & $9.85(2.84)$ & $10(7.25-12)$ & \\
\hline \multicolumn{4}{|l|}{ BMI } \\
\hline Normal weight & $8.57(2.66)$ & $8.5(7-10)$ & 0.042 \\
\hline Overweight & $10.22(2.69)$ & $10(8-13)$ & \\
\hline Obesity & $9.71(3.12)$ & $10(8-12)$ & \\
\hline \multicolumn{4}{|l|}{ Marital status } \\
\hline Single & $9.77(2.88)$ & $10(8-12)$ & 0.555 \\
\hline In relationship & $9.48(2.82)$ & $9.5(7-12)$ & \\
\hline \multicolumn{4}{|l|}{ Education } \\
\hline Primary & $10.5(2.48)$ & $10.5(9-12)$ & 0.022 \\
\hline Secondary & $9.9(2.87)$ & $10(7.75-12)$ & \\
\hline Higher & $8.53(2.78)$ & $8(6.25-10)$ & \\
\hline \multicolumn{4}{|l|}{ Place of residence } \\
\hline City & $9.06(2.79)$ & $9(7-12)$ & 0.043 \\
\hline Countryside & $10.2(2.8)$ & $10(8-12)$ & \\
\hline \multicolumn{4}{|c|}{ Occupational activity } \\
\hline Working & $9(2.68)$ & $9(7-I I)$ & 0.011 \\
\hline Not working & $10.38(2.87)$ & $11(9-13)$ & \\
\hline \multicolumn{4}{|l|}{ Hypertension } \\
\hline Stage I & $8.47(2.53)$ & $8(7-9)$ & 0.077 \\
\hline Stage 2 & $9.56(3.09)$ & $9.5(7-12)$ & \\
\hline Stage 3 & $10.3(2.43)$ & $10(9-12)$ & \\
\hline
\end{tabular}

Notes: anann-Whitney $U$ test or Kruskal-Wallis test. $P$, level of statistical significance.

Abbreviations: BMI, body mass index; ESS, Epworth Sleepiness Scale; M, mean; Me, median; QI, first quartile; Q3, third quartile.

modern society. ${ }^{17,41}$ General population studies in Asia ${ }^{42,43}$ and in Europe ${ }^{33,44}$ have shown that the proportion of people suffering from sleep problems, including insomnia, is significantly lower than in Poland, ${ }^{45}$ where the majority reports subjective insomnia. These differences are most likely due to differences in diagnostic methods. The proportion of people with insomnia is higher among the population of people visiting their general practitioner (GP) than in the general population, ${ }^{30,46}$ perhaps because people seeing their GP have other diseases and disorders that may affect the risk of developing insomnia. Over $40 \%$ of the patients seeing their GP for hypertension were found to have poor sleep ${ }^{8}$ or insomnia; ${ }^{47}$ these proportions are similar to those obtained in this study. 
Table 4 Correlations between sociodemographic variables and the result of the AIS questionnaire

\begin{tabular}{|c|c|c|c|}
\hline \multirow[t]{2}{*}{ Variables } & \multicolumn{2}{|c|}{$\begin{array}{l}\text { Spearman correlation } \\
\text { coefficient (rho) }\end{array}$} & \multirow[t]{2}{*}{$P^{a}$} \\
\hline & $M(S D)$ & $M e(Q I-Q 3)$ & \\
\hline Age & \multicolumn{2}{|l|}{ rho $=0.337$} & 0.001 \\
\hline Disease duration & \multicolumn{2}{|l|}{ rho $=0.177$} & 0.078 \\
\hline \multicolumn{4}{|l|}{ Sex } \\
\hline Female & $7.7(4.7)$ & $6.5(4-I I)$ & 0.716 \\
\hline Male & $7.61(4.76)$ & $8(3.25-10)$ & \\
\hline \multicolumn{4}{|l|}{ BMI } \\
\hline Normal weight & $6.8(5.25)$ & $4.5(3-9.5)$ & 0.137 \\
\hline Overweight & $8.22(4.04)$ & $9(5-10)$ & \\
\hline Obesity & $7.52(5.37)$ & $6(4-I I)$ & \\
\hline \multicolumn{4}{|l|}{ Marital status } \\
\hline Single & $8.38(4.92)$ & $8(4.75-11)$ & 0.113 \\
\hline In relationship & $6.98(4.45)$ & $6.5(3-9.25)$ & \\
\hline \multicolumn{4}{|l|}{ Education } \\
\hline Primary & $8.64(4.68)$ & $8.5(5-11.75)$ & 0.07 I \\
\hline Secondary & $8.06(4.75)$ & $8(4-10.25)$ & \\
\hline Higher & $6.27(4.5 \mathrm{I})$ & $4(3-8.75)$ & \\
\hline \multicolumn{4}{|l|}{ Place of residence } \\
\hline City & $7.18(4.05)$ & $7(3.5-10)$ & 0.621 \\
\hline Countryside & $8.14(5.31)$ & $8(4-I I)$ & \\
\hline \multicolumn{4}{|c|}{ Occupational activity } \\
\hline Working & $6.13(3.88)$ & $5(3-8)$ & $<0.001$ \\
\hline Not working & $9.51(5)$ & $10(6-12)$ & \\
\hline \multicolumn{4}{|l|}{ Hypertension } \\
\hline Stage I & $6.71(4.37)$ & $5(4-8)$ & 0.185 \\
\hline Stage 2 & $7.3(5.08)$ & $6.5(3-10.75)$ & \\
\hline Stage 3 & $8.67(4.23)$ & $9(6-10)$ & \\
\hline
\end{tabular}

Notes: ${ }^{a}$ Mann-Whitney $U$ test or Kruskal-Wallis test. $P$, level of statistical significance.

Abbreviations: AIS, Acceptance of Illness Scale; BMI, body mass index; M, mean; Me, median; QI, first quartile ; Q3, third quartile.
Studies by Al-Tannir et $\mathrm{al}^{9}$ and Hinz et $\mathrm{al}^{33}$ showed that adults who were not occupationally active were more likely to complain of sleep problems, which was corroborated in this study. Alebiosu et $\mathrm{al}^{8}$ confirmed that patients who have been ill for a long time are more likely to complain about sleep problems, and we found that patients with longer duration of hypertension were more likely to complain of daytime sleepiness and insomnia.

Egyptian $^{31}$ and Chinese ${ }^{43}$ studies found that people who are single or divorced often suffer from insomnia, but our results did not corroborate this. We also found no evidence that insomnia was more prevalent in rural residents than urban residents..$^{43} \mathrm{We}$ did, however, find that people with a BMI of $>25$ were more likely to complain of insomnia, corroborating the finding of Hinz et al. ${ }^{33}$

Recent research studies in samples of elderly people ${ }^{31}$ and patients with chronic diseases ${ }^{47}$ such as diabetes, ${ }^{36}$ rheumatoid arthritis, ${ }^{34}$ and Parkinson's disease ${ }^{32}$ have shown that sleep problems have a negative effect on QOL, which is also confirmed in this study. To the best of our knowledge, this study is the first to evaluate the relationship between insomnia, sleepiness, and QOL in patients with hypertension.

It should be recommended to assess sleep patterns and behaviors in patients and plan their care around these responses. Assessment of sleep routines and practical strategies that may improve patients' sleep may be essential for a patient and may be important as a part of nursing care. In the case of long-time sleep problems, the medical team should recommend a medication regimen.

There are some potential limitations of this study that are discussed briefly. First of all, in this study, there were mixed sleep disturbances including insomnia and sleepiness

Table 5 Correlations for sleep disturbances and QOL

\begin{tabular}{|c|c|c|c|c|}
\hline \multirow[t]{3}{*}{ WHOQOL-BREF } & \multicolumn{4}{|c|}{ Correlations with questionnaires } \\
\hline & \multicolumn{2}{|l|}{ ESS } & \multicolumn{2}{|l|}{ AIS } \\
\hline & Pearson correlation & $P$-value & Pearson correlation & $P$ \\
\hline QOL perception & -0.478 & $<0.001$ & -0.432 & $<0.001$ \\
\hline Health perception & -0.278 & 0.005 & -0.295 & 0.003 \\
\hline Physical domain & -0.565 & $<0.001$ & -0.582 & $<0.001$ \\
\hline Psychological domain & -0.554 & $<0.001$ & -0.52 & $<0.001$ \\
\hline Social domain & -0.544 & $<0.001$ & -0.446 & $<0.001$ \\
\hline Environmental domain & -0.546 & $<0.001$ & -0.437 & $<0.001$ \\
\hline
\end{tabular}

Note: $P$, level of statistical significance.

Abbreviations: AIS, Acceptance of Illness Scale; ESS, Epworth Sleepiness Scale; QOL, quality of life; WHOQOL-BREF, World Health Organization Quality of Life-Brief. 

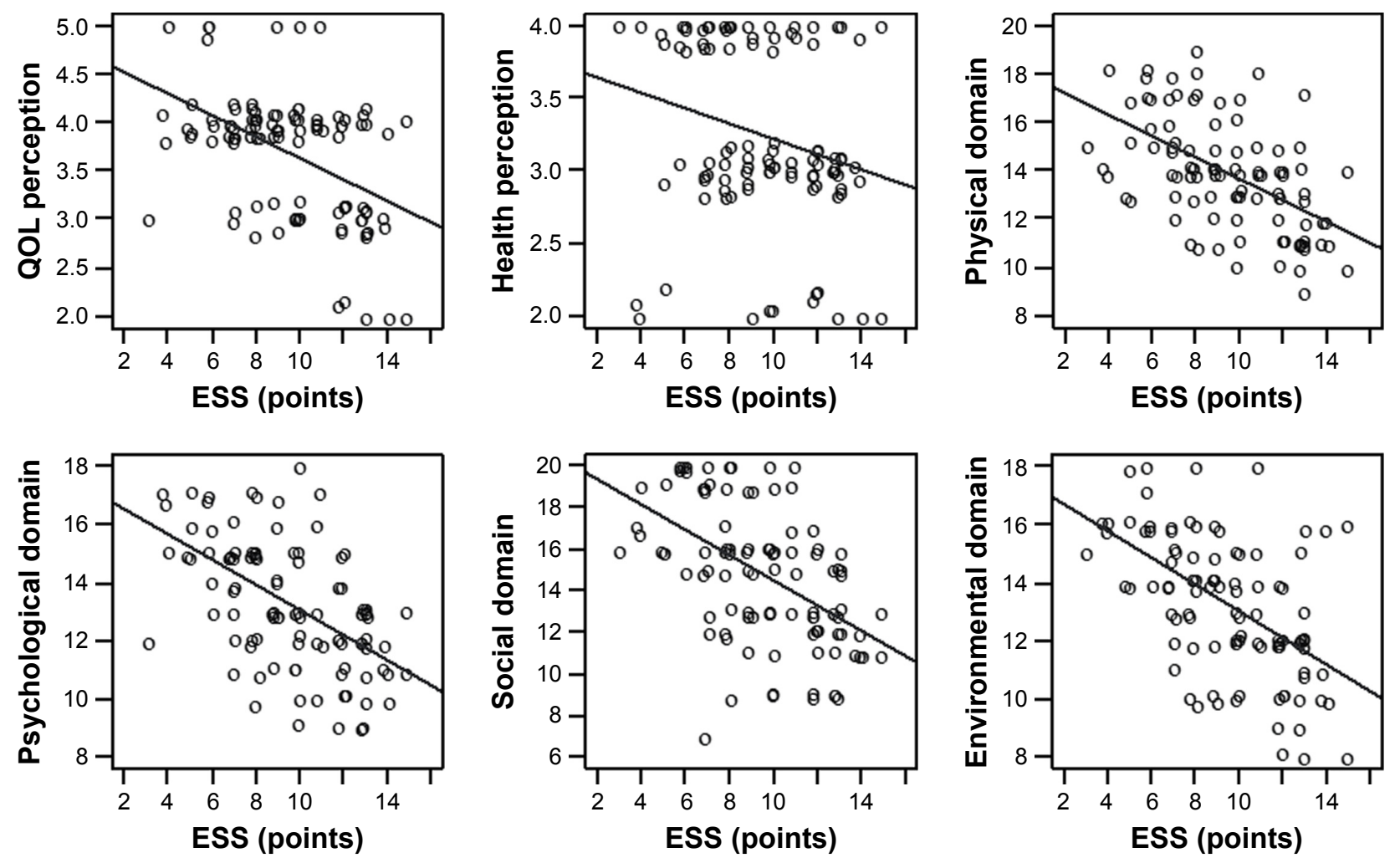

Figure I Correlations for sleep disturbances in ESS and QOL.

Abbreviations: ESS, Epworth Sleepiness Scale; QOL, quality of life.

among patients with hypertension. It should be pointed out that sleepiness is not a typical symptom of insomnia and probably it would have been better to specify study outcomes and evaluate tiredness. The best solution would be to analyze the relationship between insomnia and HRQOL in these patients with hypertension (without sleepiness) as the main outcome. Also, sleepiness must be taken into account as a possible symptom of undiagnosed sleep disorders in general, such as obstructive sleep apnea. Another limitation is that the study lacks an external control group, which would be valuable to compare the obtained results. Last but not least, objective tools such as respiratory polygraphy or polysomnography for diagnosis of sleep-disordered breathing were not used; however, they should be considered in the future studies.

\section{Conclusion}

This observational study shows that sleep problems have a significant negative impact on the QOL of patients with hypertension. Sleep problems have a significant negative impact on the QOL in patients with hypertension, especially in the physical domain of the QOL questionnaire. The occurrence of sleep problems in patients with hypertension is influenced by older age, primary education, overweight, occupational activity, and longer duration of illness.

\section{Abbreviations}

AIS, Athens Insomnia Scale; ESS, Epworth Sleepiness Scale; GP, general practitioner; HRQOL, health-related quality of life; ICSD, International Classification of Sleep Disorders; QOL, quality of life; STROBE, STrengthening the Reporting of OBservational studies in Epidemiology; WHOQOLBREF, World Health Organization Quality of Life-Brief.

\section{Data sharing statement}

All co-authors have agreed to the submission and publication of this manuscript. The authors are able to provide a signed consent if required by the Journal Editor. The authors confirm that all data underlying the findings described in this manuscript are fully available to all interested researchers upon request.

\section{Acknowledgments}

There were no other contributors to the article than the authors as well as there was no writing assistance regarding this study. The certificated English language services were provided by 
an academic highly qualified native English speaker. This study was conducted under a research project funded by the Ministry of Science and Higher Education in Poland as a part of a statutory grant of the Wroclaw Medical University for maintaining research potential (no ST.E020.17.050).

\section{Author contributions}

All authors of this manuscript meet the authorship criteria according to the latest guidelines of the International Committee of Medical Journal Editors (ICMJE), as well as all authors have seen and approved the manuscript being submitted and published. All authors contributed to data analysis, drafting or revising the article, gave final approval of the version to be published, and agree to be accountable for all aspects of the work.

\section{Disclosure}

The authors report no conflicts of interest in this work.

\section{References}

1. Blomstrand A, Blomstrand C, Ariai N, Bengtsson C, Björkelund C. Stroke incidence and association with risk factors in women: a 32-year follow-up of the prospective population study of women in Gothenburg. BMJ Open. 2014;4(10):e005173.

2. Islami F, Mańczuk M, Vedanthan R, et al. A cross-sectional study of cardiovascular disease and associated factors. Ann Agric Environ Med. 2011;18(2):255-259.

3. Mejía-Lancheros C, Estruch R, Martínez-González MA, et al. Impact of psychosocial factors on cardiovascular morbimortality: a prospective cohort study. BMC Cardiovasc Disord. 2014;14(1):135.

4. National cholesterol education program (NCEP) expert panel on detection, evaluation, and treatment of high blood cholesterol in adults (adult treatment panel III). Third report of the national cholesterol education program (NCEP) expert panel on detection, evaluation, and treatment of high blood cholesterol in adults (adult treatment panel III) final report. Circulation. 2002;106(25):3143-3421.

5. O'Donnell MJ, Xavier D, Liu L, et al. Risk factors for ischaemic and intracerebral haemorrhagic stroke in 22 countries (the INTERSTROKE study): a case-control study. The Lancet. 2010;376(9735):112-123.

6. Yusuf S, Hawken S, Ounpuu S, et al. Effect of potentially modifiable risk factors associated with myocardial infarction in 52 countries (the INTERHEART study): case-control study. The Lancet. 2004; 364(9438):937-952.

7. Mills KT, Bundy JD, Kelly TN, et al. Global disparities of hypertension prevalence and control: a systematic analysis of population-based studies from 90 countries. Circulation. 2016;134(6):441-450.

8. Alebiosu OC, Ogunsemi OO, Familoni OB, Adebayo PB, Ayodele OE. Quality of sleep among hypertensive patients in a semi-urban Nigerian community: a prospective study. Postgrad Med. 2009;121(1):166-172.

9. Al-Tannir M, Kobrosly SY, Al-Badr AH, Salloum NA, Altannir YM, Sakkijha H. Characterizing sleeping habits and disturbances among Saudi adults. Saudi Med J. 2016;37(12):1372-1380.

10. Bansil P, Kuklina EV, Merritt RK, Yoon PW. Associations between sleep disorders, sleep duration, quality of sleep, and hypertension: results from the National Health and Nutrition Examination Survey, 2005 to 2008. J Clin Hypertens. 2011;13(10):739-743.

11. Hanus JS, Amboni G, Rosa Mida, Ceretta LB, Tuon L. The quality and characteristics of sleep of hypertensive patients. Rev ESc Enferm USP. 2015;49(4):0596-0602.
12. Lu K, Chen J, Wang L, et al. Association of sleep duration, sleep quality and shift-work schedule in relation to hypertension prevalence in Chinese adult males: a cross-sectional survey. Int J Environ Res Public Health. 2017;14(2):210.

13. Calhoun DA, Harding SM. Sleep and hypertension. Chest. 2010;138(2): 434-443.

14. Thomas SJ, Calhoun D. Sleep, insomnia, and hypertension: current findings and future directions. J Am Soc Hypertens. 2017;11(2): $122-129$.

15. Aggarwal B, Makarem N, Shah R, et al. Effects of inadequate sleep on blood pressure and endothelial inflammation in women: findings from the American Heart Association go red for women strategically focused Research network. J Am Heart Assoc. 2018;7(12):e008590.

16. Talarowska P, Klocek M, Gasowski J. [OP.7A.05] sleep disturbances and resistant hypertension in a large sample of treated hypertensive subjects - POL-FOKUS study. J Hypertens. 2017;35:e63.

17. Rod NH, Vahtera J, Westerlund H, et al. Sleep disturbances and cause-specific mortality: results from the GAZEL cohort study. Am J Epidemiol. 2011;173(3):300-309.

18. Li Y, Yang Y, Li Q, et al. The impact of the improvement of insomnia on blood pressure in hypertensive patients. J Sleep Res. 2017;26(1): 105-114.

19. Ohayon MM. Epidemiological overview of sleep disorders in the general population. Sleep Med Res. 2011;2(1):1-9.

20. Roth T. Insomnia: definition, prevalence, etiology, and consequences. J Clin Sleep Med JCSM Off Publ Am Acad Sleep Med. 2007; 3(5 Suppl):S7-S10.

21. Sateia MJ. International Classification of sleep disorders-third edition: highlights and modifications. Chest. 2014;146(5):1387-1394.

22. Khanna D, Tsevat J. Health-related quality of life - an introduction. Am J Manag Care. 2007;13 Suppl 9:S218-S223.

23. Karimi M, Brazier J. Health, health-related quality of life, and quality of life: what is the difference? Pharmacoeconomics. 2016;34(7): 645-649.

24. Németh G. Health related quality of life outcome instruments. Eur Spine J. 2006;15 Suppl 1(S1):S44-S51.

25. Bardage $C$, Isacson DG. Hypertension and health-related quality of life. An epidemiological study in Sweden. J Clin Epidemiol. 2001;54(2): $172-181$.

26. Trevisol DJ, Moreira LB, Kerkhoff A, Fuchs SC, Fuchs FD. Healthrelated quality of life and hypertension: a systematic review and meta-analysis of observational studies. J Hypertens. 2011;29(2): 179-188.

27. Zygmuntowicz M, Owczarek A, Elibol A, Olszanecka-Glinianowicz M, Chudek J. Blood pressure for optimal health-related quality of life in hypertensive patients. J Hypertens. 2013;31(4):830-839.

28. Raskeliene V, Babarskiene MR, Macijauskiene J, Seskevicius A. [Impact of duration and treatment of arterial hypertension on healthrelated quality of life]. Medicina. 2009;45(5):405-411.

29. Topór-Mądry R. Chronic Diseases. Burden, quality of life and economic consequences. Public Health Manag. 2011;1:25-49.

30. Zailinawati AH, Mazza D, Teng CL. Prevalence of insomnia and its impact on daily function amongst Malaysian primary care patients. Asia Pac Fam Med. 2012;11(1):9.

31. Abd Allah ES, Abdel-Aziz HR, Abo El-Seoud AR. Insomnia: prevalence, risk factors, and its effect on quality of life among elderly in Zagazig City, Egypt. J Nurs Educ Pract. 2014;4(8):52.

32. Havlikova E, van Dijk JP, Nagyova I, et al. The impact of sleep and mood disorders on quality of life in Parkinson's disease patients. J Neurol. 2011;258(12):2222-2229.

33. Hinz A, Glaesmer H, Brähler E, et al. Sleep quality in the general population: psychometric properties of the Pittsburgh sleep quality index, derived from a German community sample of 9284 people. Sleep Med. 2017;30:57-63.

34. Purabdollah M, Lakdizaji S, Rahmani A, Hajalilu M, Ansarin K. Relationship between sleep disorders, pain and quality of life in patients with rheumatoid arthritis. J Caring Sci. 2015;4(3):233-241. 
35. Roustaei N, Jamali H, Jamali MR, Nourshargh P, Jamali J. The association between quality of sleep and health-related quality of life in military and Non-military women in Tehran, Iran. Oman Med J. 2017;32(2): 124-130.

36. Zhang P, Lou P, Chang G, et al. Combined effects of sleep quality and depression on quality of life in patients with type 2 diabetes. BMC Fam Pract. 2016;17(1):40.

37. Johns MW. A new method for measuring daytime sleepiness: the Epworth Sleepiness Scale. Sleep. 1991;14(6):540-545.

38. Soldatos CR, Dikeos DG, Paparrigopoulos TJ. Athens insomnia scale: validation of an instrument based on ICD-10 criteria. J Psychosom Res. 2000;48(6):555-560.

39. Wołowicka I, Jaracz K. Polish version of the WHOQOL - WHOQOL 100 and WHOQOL BREEF. In: Quality of Life in Medical Sciences. Poznan, Poland: Poznan Medical University Publisher; 2001:231-238.

40. Hinkle DE, Wiersma W, Jurs SG. Applied Statistics for the Behavioral Sciences. 5th ed. Boston: Houghton Mifflin; 2002.

41. Wojtas AaCiszewski S. Epidemiology of insomnia. Psychiatry. 2011; 8(3):79-83.
42. Cao XL, Wang SB, Zhong BL, et al. The prevalence of insomnia in the general population in China: a meta-analysis. PLoS One. 2017;12(2): e0170772.

43. Tang J, Liao Y, Kelly BC, et al. Gender and regional differences in sleep quality and insomnia: a general population-based study in Hunan Province of China. Sci Rep. 2017;7(1):43690.

44. Ohayon MM, Sagales T. Prevalence of insomnia and sleep characteristics in the general population of Spain. Sleep Med. 2010;11(10):1010-1018.

45. Nowicki Z, Grabowski K, Cubała WJ, et al. Prevalence of self-reported insomnia in general population of Poland. Psychiatr Pol. 2016;50(1): $165-173$.

46. Bhaskar S, Hemavathy D, Prasad S. Prevalence of Chronic insomnia in adult patients and its correlation with medical comorbidities. J Family Med Prim Care. 2016;5(4):780-784.

47. Katz DA, Mchorney CA. The relationship between insomnia and health-related quality of life in patients with chronic illness. J Fam Pract. 2002;51(3):229-235.
Clinical Interventions in Aging

\section{Publish your work in this journal}

Clinical Interventions in Aging is an international, peer-reviewed journal focusing on evidence-based reports on the value or lack thereof of treatments intended to prevent or delay the onset of maladaptive correlates of aging in human beings. This journal is indexed on PubMed Central, MedLine,

\section{Dovepress}

CAS, Scopus and the Elsevier Bibliographic databases. The manuscript management system is completely online and includes a very quick and fair peer-review system, which is all easy to use. Visit http://www.dovepress. com/testimonials.php to read real quotes from published authors. 